Manfred Nagl

\title{
Einführung in die Programmiersprache Ada
}

Skriptum für Hörer aller Fachrichtungen

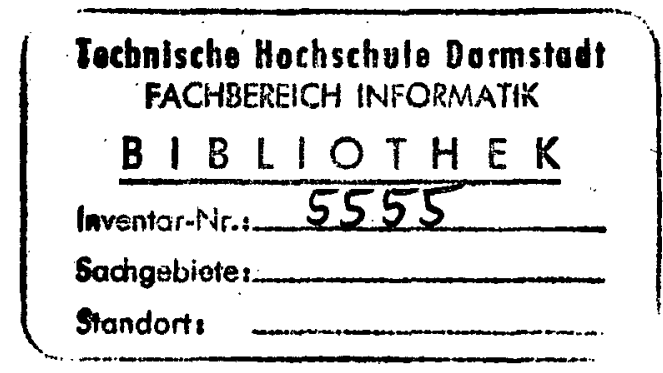

V

Friedr. Vieweg \& Sohn Braunschweig/Wiesbaden 


\section{INHALT}

1. EINFÜHRUNG UND GRUNDBEGRIFFE $\ldots \ldots \ldots \ldots \ldots \ldots \ldots \ldots \ldots \ldots \ldots \ldots \ldots \ldots$

1.1 Geschichte der Entwicklung von Ada $\ldots \ldots \ldots \ldots \ldots \ldots \ldots \ldots$. 1

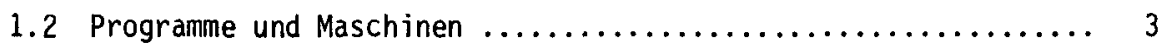

1.3 Software-Engineering und Phasen der Software-Entwicklung $\ldots . .5$

1.4 Gütekriterien für Programme $\ldots \ldots \ldots \ldots \ldots \ldots \ldots \ldots \ldots \ldots, 10$

1.5 Hilfsmittel der Programmerstellung / APSE-Projekt ......... 13

1.6 Syntaxnotation und Grundsymbole .................... 19

1.7 Bezeichner, Zahlen und Zeichenketten ................. 23

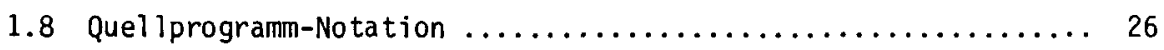

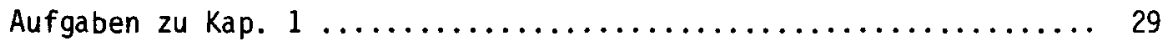

2. OBJEKTE FüR DAS PRUGRAMMIEREN IM KLEINEN $\ldots \ldots \ldots \ldots \ldots \ldots \ldots \ldots, 30$

2.1 Einfache 0bjekt- und Typdeklarationen $\ldots \ldots \ldots \ldots \ldots \ldots \ldots, 31$

2.2 Ausdrücke, Wertzuweisungen und Anweisungsfolgen .......... 36

2.3 Bedingte Anweisungen und Auswahl anweisungen (if, case) ..... 40

2.4 Zählschleifen und Schleifen mit Bedingungen (for, while) .... 44

2.5 Ineinanderschachtelung von Kontrolistrukturen und

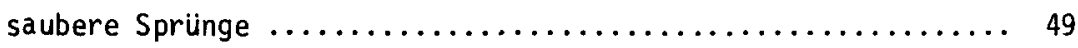

2.6 Blockstruktur, Gültigkeit, Sichtbarkeit ............... 58

2.7 Funktionen und Operatoren ........................ 63

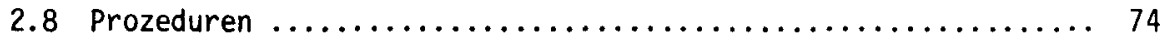

2.9 Ausnahmebehandlung bei Blöcken und Prozeduren ............ 83

2.10 Text-Ein-/Ausgabe ............................. 91

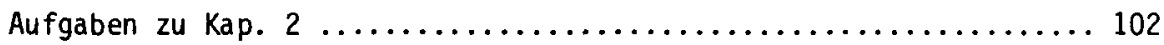

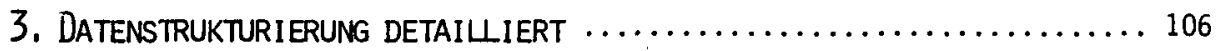

3.1 Basisdatentypen BOOLEAN, CHARACTER und allgemeine Aufzählungstypen ................................. 107

3.2 Feldtypen mit spezifizierten Grenzen .................. 114

3.3 Feldtypen mit unspezifizierten Grenzen und der Datentyp STRING ................................. 123

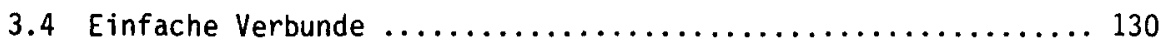

3.5 Verbunde mit Diskriminanten, variante Verbunde ........... 135

3.6 Das Typenkonzept von Ada, Untertypen, abgeleitete Typen ..... 145

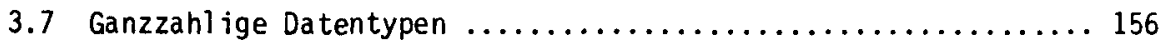


3.8 Typen numerisch-reeller Zahlen: Gleitpunkttypen,

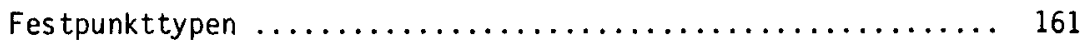

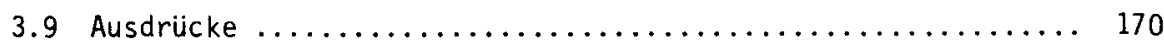

3.10 Zeigertypen und Haldenobjekte, Listenverarbeitung ........ 175

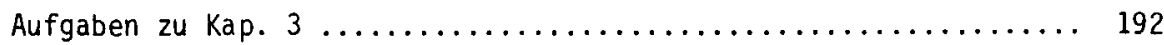

4. PROGRAMMIEREN IM GROSSEN $\ldots \ldots \ldots \ldots \ldots \ldots \ldots \ldots \ldots \ldots \ldots \ldots \ldots \ldots$

4.1 Generische Unterprogramme und das generische Prinzip ...... 197

4.2 Pakete, die Ada-Notation für Moduln ................ 203

4.3 Programmstruktur, Giiltigkeit, Sichtbarkeit ............ 215

4.4 Getrennte Obersetzung ...................... 222

4.5 Modulkonzepte und Umsetzung in Ada $\ldots \ldots \ldots \ldots \ldots \ldots \ldots \ldots . \ldots \ldots$

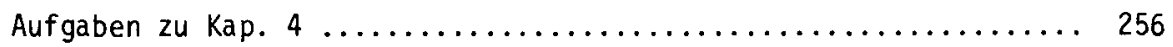

5. NEBENLÄUf IGE PROGRAMMIERUNG $\ldots \ldots \ldots \ldots \ldots \ldots \ldots \ldots \ldots \ldots \ldots \ldots \ldots \ldots \ldots$

5.1 Tasks als Programmeinheiten für nebenläufige Programierung . 260

5.2 Das Rendezvous-Konzept ..................... 267

5.3 Nichtdeterministische Auswahl zwischen Alternativen ....... 272

5.4 Verzögerung, Unterbrechung, Ausnahmebehandlung, Beendigung .. 280

5.5 Tasktypen, Entry-Familien, Implementierungsaspekte ....... 289

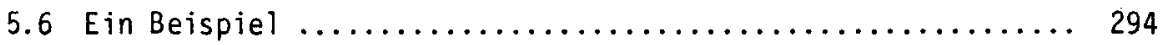

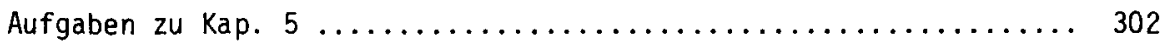

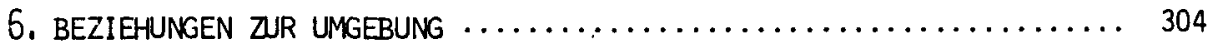

6.1 Ein-/Ausgabe und Dateiverwaltung ................ 305

6.2 Angaben zur Darstellung auf der Basismaschine .......... 318

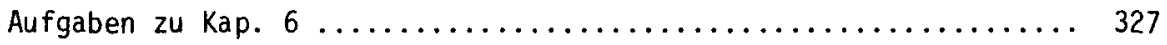

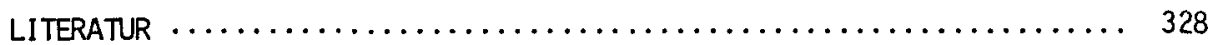

\section{ANHÄNGE}

Vordefinierte Pragmas ........................... 332

Vordefinierte Ausnahmen, zug. Laufzeitüberprüfungen ......... 333

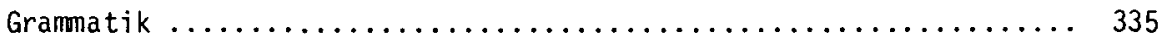

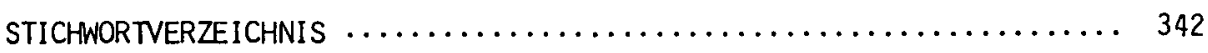

